\title{
Obstacles to undertaking research and their effect on research output: a survey of faculty members' views at Shiraz University of Medical Sciences
}

Z. Karimian, ' Z. Sabbaghian, ${ }^{7}$ A. Salehi' and B.S. Sedghpour ${ }^{2}$

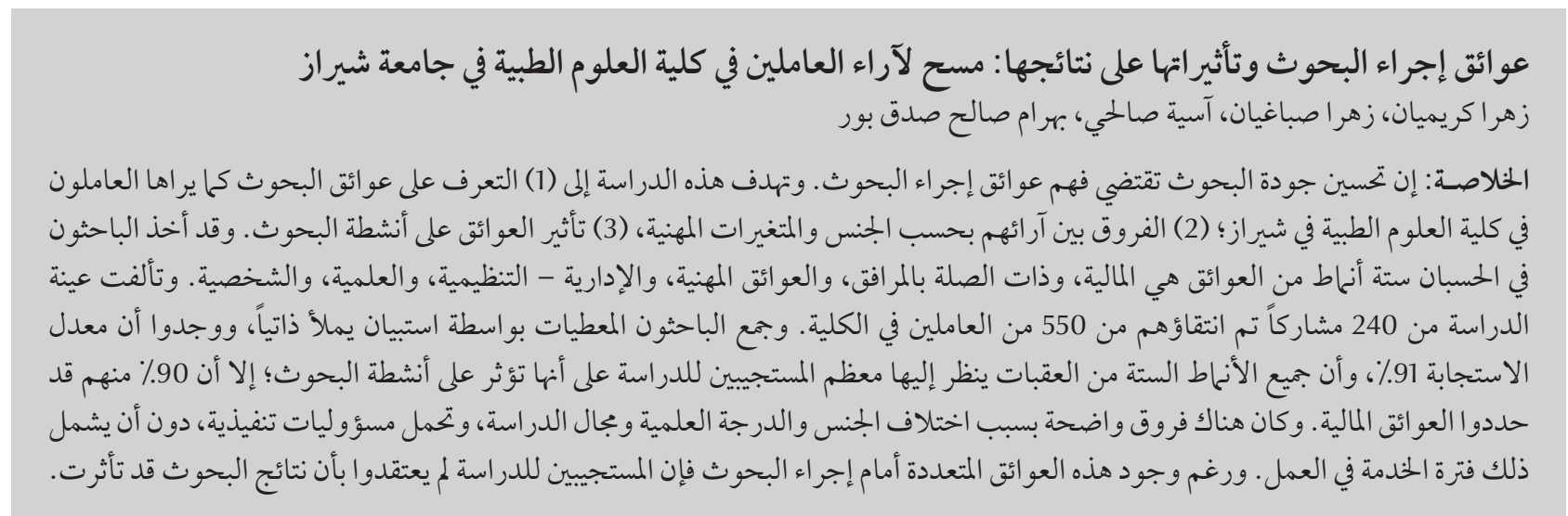

ABSTRACT To improve the quality of research, it is necessary to understand the obstacles to undertaking research. This study aimed to identify: i) internal obstacles to research as considered by faculty members at Shiraz University of Medical Sciences; ii) differences between their viewpoints by gender and professional variables; and iii) the effect of these obstacles on research activity. Six types of obstacle were considered: financial, facility-related, occupational, managerial-organizational, scientific and personal. The study sample consisted of 240 participants selected from all 550 faculty members of the University. Data were collected by self-administered questionnaire; the response rate was 91\%. All 6 types of obstacle were considered to affect research activities by most of the respondents, with $90 \%$ identifying financial obstacles. There were significant differences by gender, scientific rank, field of study, and holding executive responsibilities but not for durations of work experience. Despite these numerous obstacles to conducting research, respondents did not think their research output was affected.

Obstacles à la conduite d'une recherche et leur effet sur le résultat de la recherche : enquête sur les points de vue des membres du corps enseignant de l'Université des Sciences médicales de Chiraz

RÉSUMÉ Pour améliorer la qualité de la recherche, il est nécessaire de comprendre les obstacles à la conduite d'un tel travail. La présente étude visait à identifier : i) des obstacles internes à la recherche du point de vue des membres du corps enseignant de l'Université des Sciences médicales de Chiraz; ii) des différences entre leurs points de vue en fonction des sexes et des variables professionnelles; et iii) l'effet de ces obstacles sur l'activité de recherche. Six types d'obstacles ont été étudiés : les obstacles d'ordre financier, professionnel, gestionnaire ou organisationnel, scientifique et personnel et en relation avec l'établissement. L'échantillon de l'étude comptait 240 participants qui avaient été sélectionnés parmi les 550 membres du corps enseignant de l'Université. Les données ont été recueillies par auto-questionnaire ; le taux de réponse était de $91 \%$. La plupart des répondants considéraient que les six types d'obstacles influaient sur les activités de recherche, et $90 \%$ avaient identifié les obstacles financiers. Les différences entre les hommes et les femmes, le grade scientifique, les domaines d'études et le fait d'avoir des responsabilités de direction étaient significatives, contrairement aux années d'expérience professionnelle. En dépit de ces nombreux obstacles à la conduite d'un travail de recherche, les répondants ne pensaient pas que les résultats de recherche étaient affectés.

'Shiraz University of Medical Sciences, Shiraz, Fars, Islamic Republic of Iran (Correspondence to A. Salehi: Nasim.Salehi@gmail.com). ${ }^{2}$ Shahid Rajaee University, Tehran, Islamic Republic of Iran.

Received: 09/08/11; accepted: 02/11/11 


\section{Introduction}

Research is one of the main foundations of sustainable development, and the long-term development of research policies without a comprehensive research system is simply not possible [1-3]. Research is so important that indices such as the national investment in research, the number of researchers referred to the total population and the number of published papers are considered criteria in judging a country's progress [3].

The number of publications from the Islamic Republic of Iran has grown from just 736 in 1996 to 13238 in 2008 [4]; however, the country's participation in global knowledge production has not been satisfactory in terms of published papers. Furthermore, in 2005 the average participation of the Islamic Republic of Iran in knowledge production was only about $0.2 \%$, although this country is home to about $1.0 \%$ of the world's population [5]. This implies that to reach the world average in research and knowledge production, the Islamic Republic of Iran should consider strategies to increase its output, such as recruiting skilled human resources, enhancing scientific culture and infrastructure, preparing suitable research tools, and investing in targeted research fields. Lack of financing and resource distribution are key barriers to researchers in all developing countries. The research budget in a typical developed country falls somewhere between 3\% and $5 \%$ of the GNP [6], whereas in the Islamic Republic of Iran it ranges from $0.2 \%$ to $0.4 \%$ of the GNP $[7,8]$. Official bureaucracy, the quantitative orientation of research evaluation, and biases in judging research projects are other obstacles to carrying out research [3].

Lack of interaction and a common language between researchers and scientific policy-makers is another challenge in research, which can undermine the efficient application of research results [9-11]. Majumdar investigated the causes of the inapplicability of medical research in Asian countries [12]; one of the main causes identified was the incongruity between research and the actual needs of these communities.

The greatest barriers to involvement in research in medical schools according to Siemens appear to be time, availability of research mentors, formal teaching of research methodology and the perception that the student would not receive appropriate acknowledgement for work put towards a research project [13].

Uncovering obstacles to research is an important first step towards improving the quality of research. Therefore the research we report here was designed to identify internal obstacles to research activities at a large medical university in the Islamic Republic of Iran in 6 fields: financial, facility, occupational, managerial-organizational, scientific and personal. This paper attempts to answer 3 major questions:

- What are the main inter-organizational obstacles to research activities as seen by faculty members?

- Do the viewpoints faculty members about obstacles affect the quantity of their research?

- Are there differences in the viewpoints of faculty members associated with gender, scientific rank, field of study, executive responsibilities and duration of work experience?

\section{Methods}

\section{Study sample}

This study was a descriptive crosssectional survey conducted in 2008. The study population was the 550 faculty members of the 8 schools and 15 research centres of Shiraz University of Medical Sciences. The study sample consisted of 227 participants selected from the 550 faculty members by stratified random sampling. We had to select all of the academic staff of some faculties as they had only few such staff (for example the school of health services management); as a result the final sample increased from 227 to 240 participants.

\section{Data collection}

Data were collected by a self-completed, anonymous questionnaire in Farsi devised by the authors. The instrument consisted of 46 closed-ended items, demographic and occupational items, and 3 open-ended items. The responses to the closed-ended questionnaire items were chosen from a 4-point Likert-like scale where 4 = agree, 3 = agree somewhat, 2 = disagree somewhat and $1=$ disagree.

The respondents were asked about 6 types of inter-organizational obstacles to research activities: financial, facilityrelated, professional, scientific, personal and managerial-organizational.

Internal and external validity of the questionnaire were confirmed by review of the relevant scientific literature and review by 15 faculty members from the different schools and centres. The Cronbach alpha coefficient for reliability of the questionnaire was $92.8 \%$ based on in a pilot study with faculty members.

Questionnaires were distributed to all 240 participants by one of the researchers who explained the purpose of the study to them.

\section{Analysis}

The analysis of the data was intended to answer 3 basic questions about the influence of obstacles to research on faculty members' research activity. To test the first question, the single-sample $t$-test was used. The second question assessed the effect of faculty members' viewpoints on the quantity of their research activities and there was more than 1 dependent variable (number of papers and research projects). As the variables may have interacted, MANOVA (multivariate analysis of variance) with Wilks' index was therefore used. Independent-sample $t$-tests, one-way ANOVA and the Tukey test were used for the third question. 
SPSS, version 15 was used for data analysis.

\section{Results}

Of the 240 questionnaires distributed, 218 were returned fully answered (response rate $91 \%$ ).

The demographic characteristics of the sample are shown in Table 1. Just over half were male (53.3\%), the greatest proportion were assistant professors (44.1\%); 5.6\% were professors. The majority were in the medical or paramedical field ( $72.4 \%)$ and the greatest proportion were in the faculty of medicine (37.4\%) followed by nursing/ midwifery (13.2\%). Just under half had executive responsibilities (46.3\%) and $40.2 \%$ had less than 10 years' work experience while $39.3 \%$ had $11-20$ years.

With regard to the main inter-organizational obstacles to research activities, all 6 types of obstacles were reported (financial, facility-related, professional, scientific, personal, managerial-organizational $)(P<0.01)$. Table 2 shows the average percentage agreement scores for each question. The highest average agreement score was found for the financial domain and the lowest for scientific factors.

To elucidate whether faculty members' viewpoints about obstacles affected the quantity of their research, agreement rates were analysed with Wilk's lambda index. The results showed that in the faculty members' views financial obstacles had a significant effect on their research output $(P<0.03)$ while facility, professional, scientific, personal and managerial-organizational obstacles had no influence $(P>0.05)$ (Table 3$)$.

The analysis of third question sought association between faculty members' viewpoint and their gender, scientific rank, field of study, executive responsibilities, and work-experience. There were significant differences by sex, scientific rank, faculty, field of study

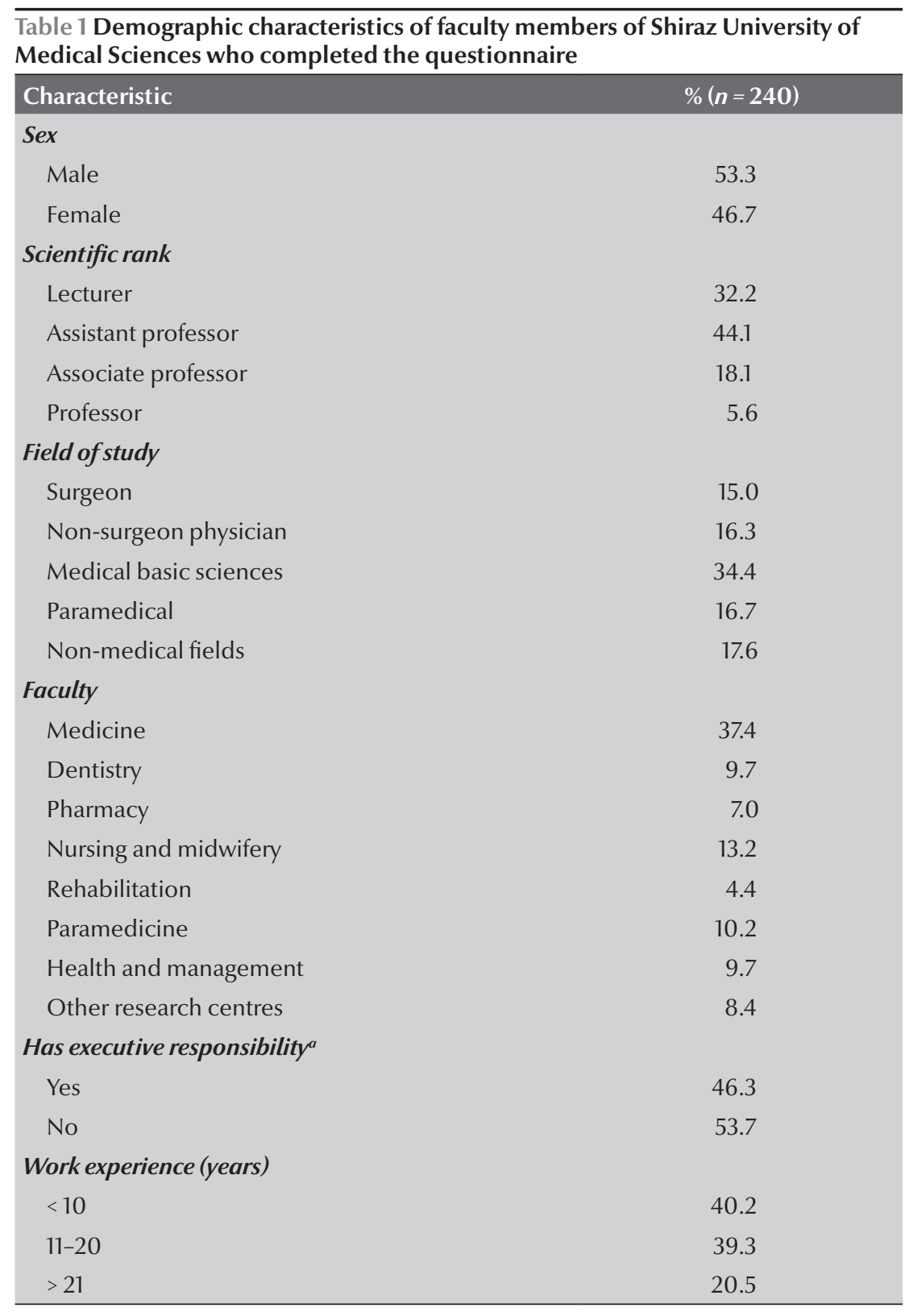

${ }^{a}$ Have additional managerial responsibilities.

and executive responsibility in faculty members' viewpoints about professional, personal and managerial obstacles $(P$ $<0.05$ ) (Table 4). However, there were no significant associations between demographic variables and the responses regarding other obstacles (Table 4). The average agreement scores for perceived obstacles were higher for instructors and assistant professors than for associate and full professors, and these differences were significantly related to professional, personal and managerialorganizational obstacles $(P<0.01)$. There were also significant differences between faculty members' viewpoints about scientific obstacles and their field of study; respondents from the basic medical sciences fields had the lowest average agreement for scientific obstacles, whereas participants from the medical surgery and nonmedical fields most often agreed that there were scientific obstacles $(P<0.01)$. In addition, faculty members who had more executive responsibilities identified fewer obstacles than other respondents, and this difference was significant for personal obstacles $(P<0.01)$. There were no significant differences between 


\begin{tabular}{|c|c|c|c|}
\hline \multirow[t]{2}{*}{ Obstacle } & \multirow[t]{2}{*}{ Item } & \multicolumn{2}{|c|}{$\%$ agreement scores } \\
\hline & & Mean & SD \\
\hline \multirow[t]{7}{*}{ Financial } & Lower funding for research activities than other activities & 90.2 & 14.9 \\
\hline & Allocation of research budget is based on reputation and influence & 89.2 & 15.9 \\
\hline & Insufficient budget for scientific research activities & 87.8 & 15.6 \\
\hline & $\begin{array}{l}\text { Unsuitable regulations and mechanisms for research proposal budgeting } \\
\text { (extreme bureaucracy) }\end{array}$ & 87.6 & 15.3 \\
\hline & $\begin{array}{l}\text { Lack of independence of university in budget allocation and a dependence } \\
\text { on governmental budget }\end{array}$ & 85.6 & 16.3 \\
\hline & Inappropriate allocation of budget and facilities of the university & 84.1 & 18.9 \\
\hline & $\begin{array}{l}\text { University unable to acquire all the available research budget due to } \\
\text { inappropriate organization }\end{array}$ & 78.8 & 18.8 \\
\hline \multirow[t]{9}{*}{ Facility-related } & Difficulty and delays in funding procurement process & 90.0 & 13.5 \\
\hline & Lack of skilled and efficient co-researchers & 87.3 & 17.2 \\
\hline & Insufficient access to up-to-date, accurate databases at the university & 86.1 & 14.9 \\
\hline & Lack of research materials & 82.1 & 19.2 \\
\hline & Lack of active research cores in the university & 81.0 & 17.9 \\
\hline & Lack of suitable computer facilities and laboratories for research & 77.9 & 19.9 \\
\hline & Lack of skilled service staff (such as typists, laboratory technicians, etc.) & 78.1 & 20.3 \\
\hline & Inefficiency of university's consultation centres & 75.7 & 19.1 \\
\hline & $\begin{array}{l}\text { Insufficient access to scientific references (libraries, scientific database } \\
\text { subscriptions, full text articles, documents, etc.) }\end{array}$ & 64.0 & 22.1 \\
\hline \multirow[t]{6}{*}{ Professional } & Involvement in routine executive activities & 87.0 & 16.5 \\
\hline & Heavy load of executive work and insufficient time for research & 86.1 & 16.5 \\
\hline & Lack of proper connection with other research organizations & 83.4 & 17.7 \\
\hline & Personal finanacial problems of faculty members & 83.1 & 20.8 \\
\hline & $\begin{array}{l}\text { Limitations to and difficulties in taking part in professional development } \\
\text { opportunities }\end{array}$ & 80.8 & 20.5 \\
\hline & Obstacles to attending seminars and conferences abroad & 73.4 & 23.4 \\
\hline \multirow[t]{7}{*}{ Scientific } & $\begin{array}{l}\text { Lack of sufficient knowledge of research methods, statistical tests, } \\
\text { questionnaire preparation, etc. }\end{array}$ & 85.6 & 18.5 \\
\hline & Lack of sufficient skills with computer hardware and software & 80.0 & 19.9 \\
\hline & Lack of sufficient skills in writing scientific papers & 79.8 & 17.8 \\
\hline & $\begin{array}{l}\text { Lack of suitable skills for preparing articles for international journals and } \\
\text { presentations at congresses }\end{array}$ & 78.9 & 20.3 \\
\hline & $\begin{array}{l}\text { Lack of suitable skills for identifying, describing, analysing, and processing } \\
\text { research problems }\end{array}$ & 76.6 & 17.8 \\
\hline & $\begin{array}{l}\text { Lack of suitable skills in searching for international articles and using } \\
\text { electronic journals }\end{array}$ & 75.8 & 20.4 \\
\hline & $\begin{array}{l}\text { Lack of suitable skills in using foreign language references in different } \\
\text { studies }\end{array}$ & 70.3 & 23.4 \\
\hline \multirow[t]{7}{*}{ Personal } & $\begin{array}{l}\text { Self-centred attitude among faculty members and lack of involvement in } \\
\text { group activities }\end{array}$ & 87.3 & 15.5 \\
\hline & Declining scientific involvementa & 84.0 & 17.0 \\
\hline & Increasing apathy among faculty members over community's problems & 81.9 & 18.9 \\
\hline & Lack of researchers' commitment to research and scientific trustworthiness & 80.4 & 17.4 \\
\hline & $\begin{array}{l}\text { Copying research ideas from other researchers rather than trying to address } \\
\text { current problems of society }\end{array}$ & 79.8 & 18.9 \\
\hline & Lack of individual motivations for research & 79.4 & 21.1 \\
\hline & Personal and family problems & 78.1 & 21.8 \\
\hline
\end{tabular}




\begin{tabular}{|c|c|c|c|}
\hline \multirow[t]{2}{*}{ Obstacle } & \multirow[t]{2}{*}{ Item } & \multicolumn{2}{|c|}{$\%$ agreement scores } \\
\hline & & Mean & SD \\
\hline \multirow{10}{*}{$\begin{array}{l}\text { Managerial and } \\
\text { organizational }\end{array}$} & Lack of effectiveness of university research in improving society's affairs & 87.7 & 15.1 \\
\hline & $\begin{array}{l}\text { Unsuitable evaluation of research performance (lack of distinction between } \\
\text { original research and fraudulent or repetitive work) }\end{array}$ & 86.9 & 16.3 \\
\hline & $\begin{array}{l}\text { Insufficient cooperation among medical sciences and other sectors of } \\
\text { research activities }\end{array}$ & 86.5 & 14.7 \\
\hline & $\begin{array}{l}\text { Redundant work and repetition of similar research at universities because } \\
\text { of inappropriate organization and lack of information }\end{array}$ & 84.4 & 15.7 \\
\hline & $\begin{array}{l}\text { Allocation of research budget to problems that havea trivial impact on } \\
\text { society }\end{array}$ & 83.4 & 17.0 \\
\hline & Unfair and unreasonable evaluation of research & 83.2 & 16.9 \\
\hline & $\begin{array}{l}\text { Innumeracy of referees and policy-makers who review the research } \\
\text { proposals }\end{array}$ & 80.3 & 18.5 \\
\hline & Lack of information about research resources, facilities and regulations & 79.5 & 17.1 \\
\hline & In effective motivation system & 79.4 & 19.2 \\
\hline & Insufficient support for researchers & 75.2 & 22.1 \\
\hline
\end{tabular}

a Becasue of other managerial responsibilities.

$S D=$ standard deviation .

faculty members' viewpoints and their work experience $(P>0.05)$.

According to the faculty members in the study, research evaluation was sometimes quantitative and aimed at annual promotion.

\section{Discussion}

\section{Obstacles}

\section{Financial}

Our study showed that the large majority of the faculty member clearly identified financial issues and lack of funding as an obstacle to research. This is not surprising as according to other research, financial issues are one of the greatest obstacles to research activities [9,10,14-16]. Majumder also stated that financial and economic obstacles were the most important problems in Asian developing countries [12].

\section{Facility-related}

In this area, the difficult and timeconsuming processes needed to obtain and prepare materials to obtain funding was the obstacle that participants identified most often. This is in agreement with Hosseini and Shmsaie [17], who surveyed facility-related obstacles in agricultural research and reported that these obstacles were considerable, and others, who noted lack of research facilities, lack of funding for libraries, out-of-date references, and lack of resources and materials for research activities as important obstacles $[12,18,19]$. An important consideration here is that in medical sciences, most research is experimental and requires laboratory facilities and materials, medical equipment, and laboratory animals and their maintenance; thus, financial support to obtain and maintain facilities and equipment is imperative.

The vast majority of the respondent also agreed that the lack of skilled coresearchers was an obstacle and Tareff reported that recruiting capable staff and co-researchers who can make efficient use of facilities is more important than procuring facilities [3].

\section{Professional}

All respondents clearly indicated that their day-to-day work and / or involvement in executive work curtailed the time they had for research. This concurs with many researchers who reported that a heavy workload was a significant obstacle to research activities [18,20-22]. Involvement in executive and official activities not only wastes large portions of faculty members' time but can also weaken their motivation for research and replace it with a tendency to do executive tasks [3]. However, our results are in contrast with those of Hosseini and Shamsaie among agriculture scientists who found that professional obstacles were the least important [17]. This discrepancy may reflect differences in the research fields of the respondents (agriculture versus health science fields). Faculty members in medical fields may work in various departments (outpatient, operating room) or in field work and may also work in their private practice so they have virtually no time for research.

\section{Scientific}

Although the majority of respondents agreed that there were scientific obstacles to conduct research, the agreement scores were the lowest, lack of adequate knowledge of scientific methods being the scientific obstacle most agreed with. Other researchers have reported that 


\begin{tabular}{|c|c|c|c|c|c|}
\hline Obstacle & Value & $F$ & Hypothesis df & Error df & $P$-value \\
\hline Financial & 0.944 & 2.624 & 4 & 356 & 0.03 \\
\hline Facility-related & 0.977 & 1.051 & 4 & 356 & 0.381 \\
\hline Professional & 0.964 & 1.644 & 4 & 356 & 0.16 \\
\hline Scientific & 0.976 & 1.086 & 4 & 356 & 0.36 \\
\hline Personal & 0.954 & 2.108 & 4 & 356 & 0.07 \\
\hline $\begin{array}{l}\text { Managerial and } \\
\text { organizational }\end{array}$ & 0.990 & 0.459 & 4 & 356 & 0.76 \\
\hline
\end{tabular}

$d f=$ degrees of freedom .

a lack of necessary knowledge about scientific research methods, a lack of information about statistical methods, and the lack of foreign language skills for research were the main scientific obstacles $[13,14,23]$.

In our study only $70.3 \%$ agreed that insufficient foreign language skills was an obstacle making it the least important obstacle; however the standard deviation was $23.4 \%$ for this item indicating a wide divergence of views.

\section{Personal}

The majority of the respondents agreed that personal obstacles existed which concurs with other studies [23-25]. Funk recognized that there is a direct relationship between personal incentives and the amount of research activity undertaken [24].

Among the personal obstacles mentioned, a self-centred attitude was the main obstacle. An earlier survey showed that experts and researchers in developing countries preferred to be more independent in their activities because of the overall atmosphere in the research environment [3]. In contrast, collaboration and teamwork activities have been reported to be essential for research development and productivity, and universities that developed teamwork activities published more research papers than universities that favoured individual activities [26]. A short-answer item in our questionnaire asked faculty members to indicate whether, according to previous experience, they preferred individual research activities or teamwork. Only
$10.6 \%$ preferred individual work, and we infer from this that if the context is suitable for group activities, researchers will welcome teamwork and interdisciplinary collaboration.

\section{Managerial-organizational}

Several studies have surveyed managerial, official and organizational obstacles such as lack of coordination among research organizations [27], inappropriate planning [28], lack of intersectoral collaboration [20], and insufficient implementation of research results $[29,30]$. Berguist and Bland stated that managerial factors within organizations, such as providing clear plans and objectives, have a direct effect on research productivity [25].-Moreover, Jens and Try found that organizational factors had a significant effect on research output, and this effect was even greater than that of the time devoted to research [31].

The 3 items most agreed as managerial-organizational obstacles were: the lack of effectiveness of research to solve actual problems in society; the inability of the system to properly evaluate research performance; and the lack of cooperation of between scientific fields in research. Some experts believe that research results are not properly presented to policy-makers, managers and executors [32]. As a result, research results are not used to influence policy and solve society's chief problems. In addition, policy-makers and managers may not take research activities seriously; there is no evidence-based decision-making culture or dynamic communication between researchers and managers. Consequently, researchers are not provided with guidance for solving society's problems [32]. In other words, the lack of implementation of research results is not only an obstacle, but also a negative consequence of complicated research systems that ultimately leads to barriers which decrease researchers' motivation.

Another managerial-organizational obstacle is the quantity-based approach to research activities and performance evaluation. The system lacks the ability to distinguish between original research and fraudulent or redundant work which affects researchers' motivation to undertaker new and pioneering research. Furthermore performance evaluation based simply on quantity of research discourages researchers from undertaking original research. As a result faculty members prefer to work on simple subjects and do repetitive and imitative research and focus on quantity.

\section{Effect of obstacles on the quantity of research}

Although the participants noted many factors as significant obstacles, they considered that these obstacles had no effect on their research performance. This could be related to 2 factors. According to faculty members' viewpoints, research evaluation is quantitative and aimed at annual promotion; therefore these obstacles do not impede their research activities. However, such policies may orient researchers toward haphazard and repetitive research activities. 


\begin{tabular}{|c|c|c|c|c|c|c|}
\hline Variable & Obstacles & $\begin{array}{l}\text { Type III sum of } \\
\text { squares }\end{array}$ & df & Mean square & $\boldsymbol{F}$ & $P$-value \\
\hline \multirow[t]{3}{*}{ Sex } & Professional & 790.40 & 1 & 790.40 & 6.77 & 0.010 \\
\hline & Personal & 913.88 & 1 & 913.88 & 11.85 & 0.001 \\
\hline & Managerial \& organizational & 5.18 & & 5.18 & 5.18 & 0.024 \\
\hline \multirow[t]{3}{*}{ Scientific rank } & Professional & 1266.942 & 3 & 422.314 & 3.679 & 0.014 \\
\hline & Personal & 971.559 & 3 & 323.853 & 4.158 & 0.008 \\
\hline & Managerial \& organizational & 713.703 & 3 & 237.901 & 3.071 & 0.030 \\
\hline \multirow[t]{4}{*}{ Faculty } & Facility-related & 2986.597 & 7 & 426.657 & 4.461 & $<0.0001$ \\
\hline & Scientific & 1972.921 & 7 & 281.846 & 2.161 & 0.042 \\
\hline & Personal & 1302.435 & 7 & 186.062 & 2.394 & 0.025 \\
\hline & Managerial \& organizational & 2480.881 & 7 & 354.412 & 5.402 & $<0.0001$ \\
\hline Field of study & Scientific & 2841.157 & 4 & 710.289 & 5.907 & $<0.0001$ \\
\hline $\begin{array}{l}\text { Executive } \\
\text { responsibility }\end{array}$ & Personal & 434.13 & 1 & 434.13 & 5.500 & 0.021 \\
\hline
\end{tabular}

The second factor is related to personal motivation. Sometimes powerful incentives can overcome external obstacles. An open-ended item in this survey asked faculty members what their starting point for research activity was. More than $50 \%$ declared that despite the problems and impediments, patient suffering and an interest in finding answers to new questions were their main motivations for research. However, the widespread perception of obstacles evident in our survey could reduce research quality and incentives in the long term.

\section{Difference between faculty members' viewpoints and socioeconomic characteristics}

According our findings, women identified research obstacles more frequently than men and this is in agreement with other research findings [33-35]. However, according to Tajari, there was no significant difference between women and men regarding obstacles to research in social sciences [36]. The discrepancy between Tajari's findings and ours may be related to differences in the male to female ratio in the 2 samples.

Faculty members who had more executive responsibilities identified fewer obstacles than other respondents, However, Tajari reported that there were no significant differences between respondents with and without executive responsibilities in the frequency of perception of personal obstacles [36]; this difference may reflect differences in the configuration of the 2 populations studied. In Tajari's study, only $25 \%$ of the participants had executive responsibilities, whereas in our research, $46.3 \%$ held executive positions.

There were no significant differences between faculty members' viewpoints and their work experience, which is consistent with the results of Tajari [36]. However, according to Hosseini and Shamsaie's study of agricultural science researchers, those with more teaching experience identified obstacles less frequently than other respondents [17]. Again, the differences between studies may reflect structural differences in the populations that were surveyed.

We found significant differences between faculty members' viewpoints on scientific obstacles depending on their field of study. Researchers in basic medical science had the lowest score for scientific obstacles, whereas clinicians in surgery and nonsurgical specialties had the highest scores. The reason for this may lie in the nature of basic sciences, which is more research based. In contrast, surgeons spend more time providing health care and clinical services, and have less time to do research or participate in research development programmes. In addition we found that language problems were mentioned more frequently in nonmedical fields than in medical and basic science fields. The reason for this difference may be the frequent use of English terms in medical teaching and training activities at Shiraz University of Medical Sciences. Our results suggest a need for faculty members to improve their English language capabilities.

\section{Study limitations}

It should be noted that our study sample may not have been representative of the entire teaching staff at this university or the faculty at any other universities in the country; as such the findings should be extrapolated with caution.

\section{Conclusion}

Our findings show that faculty members in our university consider there are numerous obstacles to conducting research, lack of funding and difficulties in funding procurement being the most important, and significantly more women identified research obstacles than 
men. Despite this our faculty members did not think their research output was affected. However, such high reporting of obstacles suggests the system does not favour research and in the long run research quality could decrease. Therefore university management needs to address this and select effective strategies to encourage more and better quality research.

\section{Acknowledgements}

We would like to thank the faculty members of Shiraz University of Medical Sciences for their participation in this research despite their always-challenging work schedules and many commitments. We would also like to thank Ms K. Shashok (AuthorAID in the Eastern Mediterranean region) for help with editing of the manuscript.

\section{References}

1. Delisle $\mathrm{H}$ et al. The role of NGOs in global health research for development. Health Research Policy and Systems, 2005, 3(1):3.

2. Hanney SR et al. The utilization of health research in policymaking: concepts, examples and methods of assessment. Health Research Policy and Systems, 2003, 1(1):2.

3. Bin Tareef A. Scientific research in Jordanian higher education institutions: an evaluation of the status and obstacles. Journal of Instructional Psychology, 2009, 36:158-61.

4. Science-Metrix. Thirty years of science - interactive trend explorer: Iran (http://www.science-metrix.com/30years/index. html\#, accessed 22 August 2012).

5. Ensafi S, Gharibi H. [Iran's knowledge production at the international level - comparison of the knowledge production situation in 15 countries]. Tehran, Iranian Research Institution for Science and Technology, 2007 [In Farsi].

6. Neufeld V, Spiegel J. Canada and Global Health Research. Canadian Journal of Public Health, 2005, 97:39-41.

7. Malekzadeh R, Mokri A, Azarmina P. medical science and research in Iran. Archives of Iranian Medicine, 2001, 4:27-39.

8. [National annual budget]. Tehran, Budget and Planning Organization Publishers, 1994:95-99 2007 [In Farsi].

9. Gennaro S. research utilization. Journal of Obstetric, Gynecologic, and Neonatal Nursing, 1994, 23:291.

10. Linde BJ. The effectiveness of three interventions to increase research utilization among practicing nurses [Thesis]: Ann Arbor, MI, University of Michigan, 1989.

11. Lacey EA. Research utilization in nursing practice -- a pilot study. Journal of Advanced Nursing, 1994, 19:987-995.

12. Majumder MAA. Issues and priorities of medical education research in Asia. Annals of the Academy of Medicine, Singapore, 2004, 33:257-263.

13. Siemens $\mathrm{R}$ et al. A survey on the attitudes towards research in medical school. BMCMedical Education, 2010, 10:4.

14. Funk SG, Tornquist EM, Champagne MT. Barriers and facilitators of research utilization. An integrative review. Nursing Clinics of North America, 1995, 30(3):395-407.

15. Ley TJ, Rosenberg LE. Removing career obstacles for young physician-scientists - loan-repayment programs. New England Journal of Medicine, 2002, 346(5):368-72.

16. Siddiqi MN. Obstacles of research in Islamic economics. Journal of King Abdulaziz University: Islamic Economics, 2008, 21:83-95

17. Hoseini M, Shamsaie E. [Research obstacles and bottlenecks from the perspective of faculty research departments of agriculture. In: Proceedings of the First Seminar in Higher Education in Allameh Tabatabai University, Islamic Republic of Iran, 1997]. Tehran, Allameh Tabatabai University, 1997:538-508 2007 [In Farsi].

18. Parahoo K. Barriers to and facilitators of research utilization among nurses in Northern Ireland. Journal of Advanced Nursing, 2000, 30:89-98.
19. Sumathipala A. Under-representation of developing countries in research literature: Ethical issues arising from a survey of five leading medical journal. BMC Medical Ethics, 2004, 5:6.

20. Miller RD. The place of research and the role of academic anaesthetists in anaesthetic departments. Best practice \& research. Clinical anaesthesiology, 2002, 16(3):353-370.

21. Kuuppelomaki M, Tuomi J. Finish nurses' views on their research activities. Journal of Clinical Nursing, 2003, 12:589-600.

22. Brown JH, Oplatka I. Bridging the research-practice gap: barriers and facilitators to research use among school principals from England and Israel. International Journal of Public Sector Management, 2005, 18:424-446.

23. Funk SG et al. Administrators' views on barriers to research utilization. Applied Nursing Research, 1995, 8:44-49.

24. Funk SG et al. BARRIERS: the barriers to research utilization scale. Applied Nursing Research, 1991, 4(1):39-45.

25. Bergquist W, Bland C. The vitality of senior faculty members. snow on the roof-fire in the furnace. Washington DC, School of Education and Human Development, George Washington University, 1997.

26. Crewe I. Reputation, research and reality: the publication records of UK Department of Politics: 1978-1984. Scientometrics, 1988, 14:235-250.

27. Bolormaa T, Bujin T, Mashbadrakh B. Report on the assessment of the master of public health training in Mongolia. Ulaanbaatar, Mongolia, Mongolian Foundation for Open Society (Soros) and the Public Health Professionals' Association of Mongolia, 2004.

28. Eric G. The role of medical school admissions committees in the decline of physician-scientists. Journal of Clinical Investigation, 2003, 111:765-767.

29. Bohannon RW, LeVeau BF. Clinicians use of research findings: A review of literature with implications for physical therapists. Physical Therapy, 1986, 66(1):45-50.

30. Briones T, Bruya MA. The professional imperative: research utilization in the search for scientifically based nursing practice. Focus on Critical Care, 1990, 17(1):78-81.

31. Jens CS, Try S. Departmental contexts and faculty research activity in Norway. Research in Higher Education, 2005, 46:593-619.

32. O'Neil J. The 10/90 gap and deficient research coordination in developing countries: case study of Mongolia and Mozambique [Dissertation]. St. Catharines, Ontario, Brock University, 2007.

33. Guelich JM, Castro BH, Rosenberg LE. A gender gap in the next generation of physician-scientists: medical student interest and participation in research. Journal of Investigative Medicine, 2002, 50:412-418.

34. Matriculating Student Questionnaire (MSQ). Washington DC, Association of American Medical Colleges, 1999-2001.

35. Andrews NC. The other physician-scientist problem: where have all the young girls gone? Nature medicine, 2002, 8(9):439-440.

36. Tajari M. [A survey of research activity obstacles in social sciences universities] [Thesis]. Tehran, Shahid Beheshti University, 2003. 